\title{
BMJ Open Joint production of research priorities to improve the lives of those with childhood onset conditions that impair learning: the James Lind Alliance Priority Setting Partnership for 'learning difficulties'
}

\author{
Ai Keow Lim (D) , ${ }^{1}$ Sinead Rhodes, ${ }^{1}$ Katherine Cowan, ${ }^{2}$ Anne O'Hare ${ }^{1}$
}

To cite: Lim AK, Rhodes S,

Cowan $\mathrm{K}$, et al. Joint production of research priorities to improve the lives of those with childhood onset conditions that impair learning: the James Lind Alliance Priority Setting Partnership for 'learning difficulties'. BMJ Open 2019;9:e028780. doi:10.1136/ bmjopen-2018-028780

- Prepublication history and additional material for this paper are available online. To view these files, please visit the journal online (http://dx.doi org/10.1136/bmjopen-2018028780).

Received 07 January 2019 Revised 17 September 2019 Accepted 19 September 2019

Check for updates

(C) Author(s) (or their employer(s)) 2019. Re-use permitted under CC BY-NC. No commercial re-use. See rights and permissions. Published by BMJ.

${ }^{1}$ Salvesen Mindroom Research Centre, Department of Child Life and Health, Centre for Clinical Brain Sciences, University of Edinburgh, Edinburgh, UK

${ }^{2}$ The James Lind Alliance, NIHR Evaluation Trials and Studies Coordinating Centre, Southampton, UK

Correspondence to

Dr Ai Keow Lim;

ak.lim@ed.ac.uk

\section{ABSTRACT}

Objectives To engage children and young people with conditions that impair learning, their parents/carers and the health, education, social work and third sector professionals to identify and prioritise research questions for learning difficulties.

Design Prospective surveys and consensus meeting guided by methods advocated by the James Lind Alliance. Setting Scotland.

Methods The Priority Setting Partnership came together through discussion and collaboration between the University of Edinburgh, Scottish charity The Salvesen Mindroom Centre and partners in the National Health Service, education services and the third sector. A steering group was established. Charity and professional organisations were recruited. Suggested questions were gathered in an open survey and from research recommendations by the National Institute for Health and Care Excellence and Scottish Intercollegiate Guidelines Network Guidance. Suggested questions and recommendations were summarised into 40 indicative research questions. These indicative questions were verified as uncertainties from research evidence. Respondents each nominated up to 10 questions as research priorities in an interim survey. The 25 highestranked questions from the interim survey were prioritised at the final priority setting workshop.

Participants 367 people submitted suggestions (29 individuals affected by learning difficulties, 147 parents/ carers and 191 professionals). 361 people participated in the interim prioritisation (41 individuals, 125 parents/ carers and 195 professionals). 25 took part in the final workshop (5 young people, 6 parents and 14 professionals).

Results Top three research priorities related to (1) upskilling education professionals, (2) best education and community environment and (3) multidisciplinary practice and working with parents. Top 10 included best early interventions, upskilling health, social and third sector professionals, support for families, identifying early signs and symptoms, effective assessments and strategies against stigma and bullying and to live independent lives.
Strengths and limitations of this study

- The first opportunity to date for individuals affected by learning difficulties, their parents/carers and the professionals who work alongside them to contribute research suggestions and have an equal say in shaping the learning difficulties research agenda.

- The involvement of professionals from the education sector: among the respondents who completed the surveys, about one-third were educational professionals.

- Young people accounted for one in five of the participants at the workshop, making this workshop one of the most inclusive of young people to date, among all those conducted by the James Lind Alliance.

- Active engagement and participation of organisations and people from across Scotland: respondents from 28 and 27 participated in the first and second surveys, respectively, out of 32 Scottish local authorities.

- Refined questions are broad, resulting mainly from the wide range of conditions covered by our definition of learning difficulties and the process of refining a large number of individual suggestions into a manageable shortlist of overarching questions.

Conclusions Results will now be a resource for researchers and funders to understand and resolve learning difficulties and improve the lives of those affected with childhood onset conditions that result in learning difficulties.

\section{INTRODUCTION}

Childhood onset conditions that affect learning are common and associated with reduced health and wellbeing, for the individual and their families. ${ }^{1}$ Many are heralded by delayed development in the preschool years ${ }^{2}$ and most developed health services operate universal and targeted 
developmental screening and surveillance programmes to facilitate early identification ${ }^{3}$ and intervention. ${ }^{4}$ Most school age children with learning difficulties will be educated in mainstream schools, in line with the UNICEF position that children with disabilities receive their education alongside their peers, ${ }^{5}$ but there is highly variable practice internationally with a sevenfold difference in children and young people (CYP) recorded as having special educational needs across Europe. ${ }^{6}$ There is underascertainment for conditions such as intellectual disability across the world, with explanations thought to include stigma and discrimination. ${ }^{7}$ The aetiology and the impact of these conditions are complex, with a host of biological ${ }^{8}$ and psychosocial determinants reducing academic attainments, ${ }^{9-11}$ which themselves result in poorer life chances, that then impact further on health and wellbeing. ${ }^{12}$ Families affected by learning difficulties can be stressed and uncertain about their choices and professionals voice concerns about their expertise in supporting those CYP with learning difficulties and educational needs. ${ }^{13}$ For the purposes of this project: a learning difficulty is 'a problem of understanding or an emotional difficulty that affects a person's ability to learn, get along with others ${ }^{14}$ and follow convention'. ${ }^{15}$ On a day-to-day basis, learning difficulties can be many things including struggling with reading, ${ }^{16}$ writing or numeracy, not being able to concentrate for long periods, losing track of time, forgetting what has just been learnt and acting impulsively. If diagnosed, a learning difficulty may be associated with many neurodevelopmental conditions such as attention deficit hyperactivity disorder (ADHD), autism spectrum disorder (ASD), developmental coordination disorder (DCD/dyspraxia), Down's syndrome, dyslexia, dyscalculia, dysgraphia, epilepsy, foetal alcohol syndrome, fragile-X syndrome, speech and language impairments, intellectual disability and Tourette syndrome. Those with learning difficulties may have no formal diagnosis or may have multifactorial causes. ${ }^{17}$ Learning difficulties are also more likely when someone has another mental health or psychiatric disorder such as depression. Paediatricians, child and adolescent mental health services and allied health professionals participate in multidisciplinary and multiagency teams and contribute to identification, diagnosis, intervention and support, but are often working from consensus best practice in the absence of a clear evidence base (National Institute for Health and Care Excellence (NICE) and Scottish Intercollegiate Guidelines Network (SIGN) Guidance on for example, ASD and ADHD).

In 2014 the British Academy of Childhood Disability (BACD) James Lind Alliance (JLA) Priority Setting Partnership (PSP) published research priorities for CYP with neurodisability, ${ }^{18}$ a heterogeneous group of individuals with some overlapping needs with those with learning difficulties. The autism PSP, initiated by Autistica, published their Top 10 in $2016 .{ }^{19}$ This encouraged our development of the learning difficulties PSP which came together through discussion and collaboration between the University of Edinburgh, the Scottish charity and funder of this PSP The Salvesen Mindroom Centre, ${ }^{15}$ and partners in the National Health Service (NHS), education services and the third sector (charity), and the JLA, ${ }^{20}$ a non-profit making initiative established in 2004 that brings individuals, carers and professionals together in PSPs to identify and prioritise the most important uncertainties, or unanswered questions. Its aim is to make sure that research funders are aware of the issues that matter most to individuals and professionals. ${ }^{20}$ The JLA methodology is the most widely employed method internationally in engaging individuals, carers and professionals in determining research priorities. ${ }^{21}$ While the scope of the childhood disability PSP was 'any ways to improve the health and/or well-being of CYP with neurodisability where there is uncertainty of the effectiveness of an intervention, therapy or procedure,${ }^{18}$ the scope of the learning difficulties PSP was broader and covered identification, causes, effects and optimum ways of supporting learning difficulties.

The learning difficulties PSP wished to pursue the strategic objective of identifying and resolving learning difficulties and understanding how best to support CYP up to age 25 years and their families. This research priority setting project was set up to identify the unanswered questions about learning difficulties from the families of CYP affected and the CYP themselves (up to age 25 years) in Scotland. These questions were to be collected alongside questions from healthcare, education, social work and third sector professionals who work with CYP with learning difficulties. The project also aimed to prioritise the questions that these stakeholders agreed to be the most important, therefore completing the project with a list of the top 10 research priorities for learning difficulties. There were a number of challenges for the learning difficulties PSP, to achieve this goal. Flexibility and innovation within the JLA framework contributed to this success. This report will discuss how these were met and the results of the learning difficulties PSP.

The challenge at outset was the use of the term 'learning difficulties' as there are many inconsistencies in the definitions of learning difficulties and the terms 'learning disabilities' and 'learning difficulties' are often used interchangeably. ${ }^{22} 23$ The definitions also vary across the USA, UK, Australia and Europe. ${ }^{24}$ In North America, the practice is to use learning disability to describe specific developmental delays or specific learning disabilities such as dyslexia, dyspraxia, dyscalculia and dysgraphia. ${ }^{24}$ Learning disability is the term preferred by UK Department of Health whereas educationalists tend to use the term learning difficulties. ${ }^{24}$ The guiding principle for the project was to use a term that would be understood by all the participants and therefore we adopted the inclusive definition, as described above, evolved by our partner charity The Salvesen Mindroom Centre. This broad definition of learning difficulties guided the priority setting process of this PSP, and we describe how it affected representation and coverage of participants. 
The second challenge was engagement with education services. Although many countries have multidisciplinary and multiagency teams working with CYP with learning difficulties and educational needs, there can be wide 'cultural' differences in terminology and outlook between health services and education. ${ }^{25}$ Families can suffer if these agencies do not work together effectively. The JLA literature is very health based, as it supports PSP research setting in applied health research as reflected in its National Institute for Health Research (NIHR) support. Earlier PSPs have tended to be around single diseases or disorders and their interventions. We describe how we met this challenge so that education professionals were effectively represented within the PSP.

The third challenge was securing engagement of the PSP with CYP affected by learning difficulties, when these conditions by their very nature, frequently affect written and oral communication. The BACD childhood disability PSP had experienced restricted engagement with CYP and had made suggestions as to how this might be improved. ${ }^{18}$ We report how we interpreted this and the outcome.

This paper describes the methodology and results of the Scottish learning difficulties PSP. The aims were to: (1) work with CYP with learning difficulties and their families and the clinicians and practitioners including education and social work to identify questions that they wanted answered in any aspect of learning difficulties; these were expected to include identification, causes, effects and the optimum interventions, treatments and supports, (2) to agree by consensus a prioritised list of questions that remained uncertainties for research, (3) to publicise the results of the PSP and process and (4) to disseminate the results and engage with researchers and funders.

\section{METHODS}

\section{Setting up the partnership: steering group}

The steering group comprised of four parent representatives $(26.7 \%)$, six health professionals (child and adolescent psychiatrist, consultant community child health paediatrician, consultant paediatrician, consultant paediatric neurologist, two speech and language therapists (SLTs) (role share) and an occupational therapist (OT) $(40.0 \%$ ), two educational professionals (a head teacher and principal educational psychologist) (13.3\%), two third sector professionals (the Chief Executives of The Salvesen Mindroom Centre and Dyslexia Scotland) $(13.3 \%)$ and a JLA senior advisor as chair $(6.7 \%)$. The 15 steering group members included four males (26.7\%) and 11 females (73.3\%). One of them is an Asian or Asian British and 14 of them are White. Compared with other JLA PSPs, the learning difficulties PSP brought innovation to this format by also involving professionals from the education sector. Each of our parent representative brought with them knowledge of different types of learning difficulties. The steering group met 13 times during the PSP process, in person or by teleconference, between October 2016 and June 2018.
The steering group agreed to obtain CYP input on an ad hoc basis, using existing groups and steering group members' contacts and consulting with family members, rather than convene a specific reference group. Input from the CYP and families was obtained at three stages of the process, namely: (1) testing of survey design to ensure it was understandable and (2) contributing to the survey and (3) prioritisation of questions.

\section{Setting up the partnership: partner organisations and societies}

The primary target audience for the surveys in this project were people living in Scotland. Potential partner organisations were identified through a process of peer knowledge and consultation, through the steering group members' networks. Charitable organisations supporting CYP with learning difficulties, the local government health and education departments and professional societies were contacted, made aware of the project and invited to become partners.

\section{Priority setting partnership process}

The four-step JLA priority setting process was followed: ${ }^{26}$ (1) gathering uncertainties; (2) data processing and verifying uncertainties; (3) interim priority setting; and (4) final priority setting (figure 1). The key principles of the JLA process were followed, including equal involvement of individuals affected by learning difficulties, parents/ carers and professionals, transparency of methods and a clear audit trail of data collected. The JLA advisor took the responsibility for ensuring the various stakeholder groups were able to contribute equally to the process. The JLA advisor explained the JLA's principles, the importance of equal input from different stakeholder groups, and how lived experience and professional expertise were of equal value to the JLA process during her presentations at the first steering group meeting and final priority setting workshop. At the first steering group meeting, parent representatives suggested it would be important to include transition into early adulthood. The steering group discussed and agreed to increase the upper age limit of CYP to 25 years and include adults who experienced learning difficulties as a child as one of the target groups.

\section{Gathering uncertainties (phase 1 survey)}

Uncertainties were gathered from CYP with learning difficulties, their parents/carers and the health, education, social work and third sector professionals who work alongside them, through a survey and from research recommendations published in relevant NICE and the SIGN guidelines. The steering group agreed to adopt a responsive approach when getting inputs from CYP. The OT and SLTs and third sector representatives on the steering group adapted the language of the paper questionnaire, information sheets and promotion materials to be CYP friendly. The SLTs were able to adapt the materials to be more accessible using their professional experience 


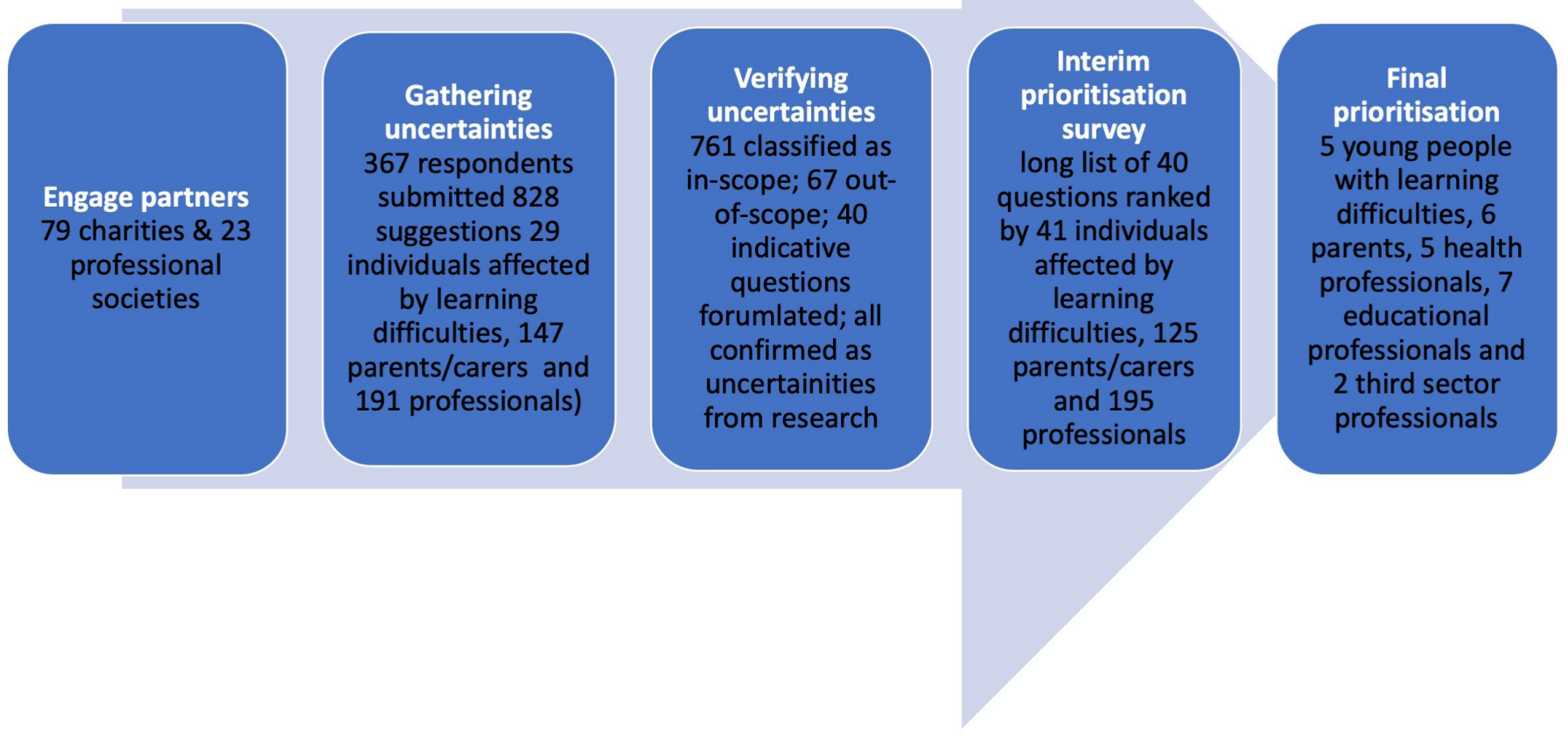

Figure 1 Flow chart showing the process and numbers of participants and research suggestions and questions at each stage.

in the area and their knowledge of the language and communication skills of young people in the schools they worked in. The OT also had conversations with some of the parents of CYP whom they worked with around the questionnaire to determine whether it was appropriate for young people to complete on their own or supported by their parents/carers. The online version was created using Jisc Online Surveys (formerly Bristol Online Survey) to comply with UK Data Protection laws. Both the online survey and paper questionnaires were piloted and refined following feedback from the steering group, including family members of the parent representatives, and a group of SLTs and OTs from NHS Lothian. The project materials can be viewed in the supplementary files: PSP protocol (online supplementary file 1), final report (online supplementary file 2), results summary sheet (online supplementary file 3), results press release (online supplementary file 4), final spreadsheet of data (online supplementary file 5), phase 1 surveys and information sheets for adults and CYP (online supplementary files 6 to 9), phase 1 survey posters and leaflet (online supplementary files 10 and 11), phase 2 surveys and information sheets for adults and CYP (online supplementary files 12 to 15 ), phase 2 survey poster and leaflet (online supplementary files 16 and 17) and project participant feedback and interviews (online supplementary file 18).

The questionnaire invited respondents to submit up to three questions they would like answered by research about learning difficulties. The questionnaire also collected basic sociodemographic information (gender, age (for CYP only), ethnicity, postcode (for matching with the Scottish Index of Multiple Deprivation (SIMD) rank and score), types of learning difficulties experienced and professions).

Invitation emails with a link to the online survey were sent to partner organisations, local government and professional societies who then advertised the survey using various media, including newsletters, Facebook, Twitter and websites. The steering group distributed printed copies of the questionnaires, information sheets and free post return envelopes at their workplaces and to their contacts. The paper questionnaires, information sheets, free post return envelopes and promotional materials were also made available at Royal Hospital for Sick Children in Edinburgh and at conferences and events for CYP with learning difficulties and their parents/carers.

The survey was launched on 8 May 2017 and initially scheduled to close on 31 July 2017. The steering group monitored responses to the survey on a regular basis. Given that the closing date was near the end of the school term in Scotland, the steering group decided to extend the deadline to 30 September 2017 to purposively target under-represented groups, including CYP with learning difficulties and adults who experienced learning difficulties as a child. For example, a video of an adult sharing his experience of living with ADHD and talking about how the project could help individuals with learning difficulties was produced and shared on social media. 
The OT and SLTs on the steering group engaged with the CYP on a one-to-one basis to complete the CYP friendly version of the questionnaire. Some CYP found it difficult to understand what is meant by research or how to phrase a question. The steering group then agreed to show as examples a list of existing questions that had been submitted by parents/carers and professionals. The language of the existing questions were adapted to be CYP friendly. These accommodations helped CYP to complete the questionnaire with the help of the OT and SLTs.

\section{Data processing}

Survey suggestions and person identification data were downloaded from the online database. The first, second and last authors independently classified the original submissions as in-scope, out-of-scope and unclear. They met and resolved disagreements through discussions. The steering group reviewed a subset of the in-scope and lists of the out-of-scope and unclear submissions. The submissions were then allocated into the nine themes identified from the entries: (1) causes, (2) identification and diagnosis, (3) effect on everyday life, (4) what helps, (5) co-occurring conditions, (6) variations in the availability and quality of provision, (7) professional training and development, (8) public awareness and (9) statistics and data. This approach enabled similar submissions to be grouped together. Where a submission related to more than one indicative question of different themes, the submission was classified under different themes. The steering group decided it was more pragmatic to create overarching preliminary indicative questions for similar submissions at this stage and agreed to collapse similar overarching questions at a later stage.

At the subsequent face-to-face meeting, the steering group discussed the list of in-scope overarching indicative questions and the out-of-scope and unclear submissions. The steering group reviewed each indicative question and considered how the survey's narrative data had been interpreted, whether the wording should be revised and whether some of the similar indicative questions could be further collapsed or merged together.

\section{Verifying uncertainties}

The veracity of whether the research questions were uncertain was checked by reference to systematic reviews and meta-analyses published in English from January 2015 to February 2018. The JLA recommends that an up-to-date systematic review is less than 3 years old. The search terms used were included as online supplementary file 19. The Diagnostic and Statistical Manual of Mental Disorders $^{27}$ and the mental disorders sections of the International Classification of Diseases ${ }^{28}$ were referred to when selecting the search terms. The databases searched were the Cochrane Database of Systematic Reviews (http://www.cochranelibrary.com/cochrane-databaseof-systematic-reviews/), University of York Centre for Review and Dissemination (https://www.crd.york.ac. uk/CRDWeb/), NHS Evidence (https://www.evidence. nhs.uk), Physiotherapy Evidence Database (https:// www.pedro.org.au), Joanna Briggs Institute (JBI) Database of Systematic Reviews and Implementation Reports (https://journals.lww.com/jbisrir/Pages/default.aspx) and Pubmed (https://www.ncbi.nlm.nih.gov/pubmed). The first author conducted the search and classified each reference as condition-specific, age-specific and/or intervention-specific. Condition-specific refers to papers that focused on certain conditions (eg, dyslexia, ASD, fragile $\mathrm{X}$ syndrome). Age-specific refers to papers that focused on certain age range (eg, neonates only, infants only or preterm only). Intervention-specific refers to papers that focused on specific types of interventions (eg, parenting programmes for disruptive behaviour). The second and last authors audited these data by making sure none of the existing evidence could answer any of the long list of indicative questions. The first, second and last authors reviewed the literature under single-blind review.

The first, second and last authors looked through the research recommendations of relevant NICE and SIGN guidelines. The research recommendations were matched with the indicative questions. All the research recommendations could be addressed in our long list of indicative questions. The list of indicative questions was presented back to the public for prioritisation.

\section{Interim priority setting (phase 2 survey)}

The steering group approved the 'long list' of 40 questions. The interim prioritisation survey invited CYP with learning difficulties, their parents/carers and the health, education, social work and third sector professionals who work alongside them to choose up to 10 of the 40 questions that they most wanted research to address. Respondents who participated in the first survey and had provided a contact email or postal address were invited by email to complete the online survey using an embedded survey link. The second survey was distributed to the same networks that were used in the first survey. The OT, SLTs and third sector representatives on the steering group adapted the language of the phase 2 questionnaire, information sheet and promotion materials to be CYP friendly. A few CYP completed the CYP friendly version individually. The OT and SLTs on the steering group engaged with the CYP on a one-to-one basis to complete the questionnaires because focus groups were too difficult for them.

The two respondent categories of CYP and adults who experienced learning difficulties as a child were combined with the parents/carers to form the family group. Returns in the interim prioritisation survey were categorised into one of two stakeholders: (1) family group and (2) professional group (including health, education, social work and third sector professionals). The data were entered into a spreadsheet for analysis of the most popular prioritised questions within each stakeholder group. Each question that was selected by the survey respondents was assigned a point. Points for each group were tallied separately, generating a family group total and a professional group total for 
each of the 40 questions. Within each group, the questions were reordered from highest to lowest according to the total points and assigned a new score according to their position, from 40 (for the most popular question) down to 1 (for the least popular). Questions, which had the same total, were ranked in joint place and given an average score between them. For each question, the new equally weighted scores were added together, resulting in a ranked list of shared priorities from 1 to 40 .

\section{Final priority setting}

A face-to-face workshop was convened to discuss, agree and rank a shared view of research priorities. Each steering group member was asked to identify three potential participants from their networks for the final workshop. Efforts were made to be representative in relations to gender, geographic locations, socioeconomic status and types of learning difficulties. CYP were encouraged to bring their parent, classroom assistant or teacher to support them. Six steering group members volunteered to be participants in order to help ensure a range of experiences and expertise was included. The project team reviewed the nomination list to ensure adequate and equitable representation from all stakeholder groups. Travel and accommodation requests were arranged and/ or reimbursed. Accommodations were arranged for participants who had to stay in Edinburgh the night prior to the workshop. Observers at the workshop included representatives from the steering group and from The Salvesen Mindroom Centre.

The workshop was structured based on the JLA recommended guidance. ${ }^{26}$ The participants were provided with the 25 questions in advance and asked to rank them individually in order to ensure they were familiar with the data. Three independent JLA facilitators (including the third author, who also chaired the workshop) managed all discussions, using a variation of the nominal group methodology that seeks to build consensus on the final top 10 priorities through group discussion and ranking. Participants were grouped into three mixed small groups, following which the composition of the groups was changed, and finally, all the participants worked collectively. The shortlisted questions were presented on one side of large cards and the ranked positions from each stakeholder from the interim prioritisation were displayed on the other side. Facilitators used this information to encourage debate after participants discussed their personal preferences. Traffic light colour-coded table cloths were used to help participants conceptualise the levels of priority as they worked towards ranking all of the questions. At each stage, the cards were arranged and rearranged in order of importance based on group preferences. If broad agreement was not apparent a vote was used. The final rank ordering represented the priorities set.

\section{Communication and dissemination}

The steering group developed a dissemination strategy in advance of the final priority setting workshop. The plan included producing a lay project report, detailed questions and answers for briefing key spokespeople and a partner communications guide and capturing the experiences of young people and professionals who took part in the final priority setting workshop. The results of the priority setting partnership will also be disseminated to researchers and to funding agencies.

\section{Patient and public involvement}

The JLA methodology has public and patient involvement in research. Parent representatives and health and education professionals were actively involved throughout the process; from overseeing the study as part of the steering group, to participation in the final workshop so that they had a voice in determining the final priorities. The steering group made particular efforts to approach a diverse range of CYP, their parents/carers and the professionals who work alongside them, including across types of learning difficulties experienced, geographic areas, socio-economic status and types of professions. A plain English summary and a final report of the top 10 research priorities for learning difficulties had been circulated to the partner organisations, workshop participants and survey respondents who had provided a contact email or postal address.

\section{Ethics statement}

The people who take part in the survey and priority setting stages of the work are not research participants. Therefore, ethical approval is not required. The collection, storage and processing of data are compliant with the General Data Protection Regulation.

\section{RESULTS}

Figure 1 shows the process and outcomes of the PSP. The results are discussed below for each of the four steps of the JLA priority setting partnership methodology.

\section{Gathering uncertainties (phase 1 survey)}

There were 367 respondents to the questionnaire, from whom 828 'research priorities' were proposed. Out of the 828 submissions, 761 were classified as in-scope, 65 as out-of-scope and two as unclear. The steering group agreed that the two unclear submissions might be interpreted differently by the parents and professionals and it was agreed to classify these questions as out-of-scope. The out-of-scope submissions included questions that referred to adults ageing with learning difficulties or those that referred to a local authority's economic policy and decisions around support services. The out-of-scope anonymised data were passed on to and will be taken forward by The Salvesen Mindroom Centre.

Table 1 summarises the respondent categories and professions. Out of 32 Scottish local authorities, respondents from 28 and 27 local authorities participated in the first and second surveys respectively. Parents' ethnic groups broadly reflected the ethnic make-up in Scotland (figure 2). The types of learning difficulties experienced 
Table 1 Survey respondents by groups and professions

Number of respondents (\%)

\begin{tabular}{lcc}
\hline & \multicolumn{2}{l}{ Number of respondents (\%) } \\
\cline { 2 - 3 } & $\begin{array}{l}\text { Phase 1 survey (367 } \\
\text { respondents) }\end{array}$ & $\begin{array}{l}\text { Phase 2 survey (361 } \\
\text { respondents) }\end{array}$ \\
\hline $\begin{array}{l}\text { CYP with learning } \\
\text { difficulties }\end{array}$ & $11(3.0 \%)$ & $10(2.8 \%)$
\end{tabular}

$\begin{array}{lcc}\text { Age range (in years) } & 13 \text { to } 18 & 4 \text { to } 22 \\ \text { Gender: Male } & 6(54.5 \%) & 5(50.0 \%) \\ \text { Gender: Female } & 5(45.5 \%) & 5(50.0 \%) \\ \text { Ethnicity: White } & 7(63.6 \%) & 10(100 \%) \\ \begin{array}{l}\text { Ethnicity: Asian or } \\ \text { Asian British }\end{array} & 2(18.2 \%) & - \\ \text { Ethnicity: Other } & 1(9.1 \%) & - \\ \text { Ethnicity: Prefer not } & 1(9.1 \%) & - \\ \text { to answer } & & \end{array}$

\begin{tabular}{lrc}
$\begin{array}{l}\text { Adults who } \\
\text { experienced learning } \\
\text { difficulties as a child }\end{array}$ & $18(4.9 \%)$ & $31(8.6 \%)$ \\
\hline $\begin{array}{l}\text { Gender: Male } \\
\text { Gender: Female }\end{array}$ & $5(27.8 \%)$ & $11(35.0 \%)$ \\
$\begin{array}{l}\text { Gender: Prefer not } \\
\text { to answer }\end{array}$ & $2(11.1 \%)$ & $20(65.0 \%)$ \\
\hline
\end{tabular}

$\begin{array}{lcc}\text { Ethnicity: White } & 16(88.8 \%) & 29(94 \%) \\ \text { Ethnicity: Black } & 1(5.6 \%) & -\end{array}$

African, Black

Caribbean or Black

British

$\begin{array}{lll}\text { Ethnicity: Mixed/ } & 1(5.6 \%) & - \\ \text { multiple ethnic } & & \\ \text { group } & & 2(6 \%)\end{array}$

to answer

\begin{tabular}{|ccc|}
\hline Parent and carers & $147(40 \%)$ & $125(34.6 \%)$ \\
\hline Male & $10(6.8 \%)$ & $10(8.0 \%)$ \\
\hline Female & $137(93.2 \%)$ & $115(92.0 \%)$ \\
\hline $\begin{array}{l}\text { Professionals* } \\
\text { Audiologist }\end{array}$ & $191(52 \%)$ & $195(54.0 \%)$ \\
\hline $\begin{array}{l}\text { Child and } \\
\text { adolescent mental } \\
\text { health staff }\end{array}$ & 14 & 1 \\
\hline $\begin{array}{l}\text { Classroom } \\
\text { assistant/pupil } \\
\text { support assistant }\end{array}$ & 7 & 5 \\
\hline $\begin{array}{l}\text { Clinical } \\
\text { psychologist }\end{array}$ & 5 & 3 \\
\hline $\begin{array}{l}\text { Clinician } \\
\begin{array}{l}\text { Community learning } \\
\text { disability nurse }\end{array}\end{array}$ & 3 & 3 \\
\hline $\begin{array}{l}\text { Educational } \\
\text { psychologist }\end{array}$ & 10 & 2 \\
\hline $\begin{array}{l}\text { General practitioner } \\
\text { Health visitor }\end{array}$ & 1 & 2 \\
\hline $\begin{array}{l}\text { Nurse } \\
\begin{array}{l}\text { Occupational } \\
\text { therapist }\end{array}\end{array}$ & 4 & 7 \\
\hline
\end{tabular}

Continued

\begin{tabular}{|c|c|c|}
\hline & \multicolumn{2}{|c|}{ Number of respondents (\%) } \\
\hline & $\begin{array}{l}\text { Phase } 1 \text { survey ( } 367 \\
\text { respondents) }\end{array}$ & $\begin{array}{l}\text { Phase } 2 \text { survey ( } 361 \\
\text { respondents) }\end{array}$ \\
\hline Optometrist & 1 & 1 \\
\hline Paediatrician & 14 & 25 \\
\hline Physician & 2 & 0 \\
\hline Physiotherapist & 4 & 1 \\
\hline Psychiatrist & 16 & 4 \\
\hline School nurse & 3 & 0 \\
\hline $\begin{array}{l}\text { Speech and } \\
\text { language therapist }\end{array}$ & 15 & 23 \\
\hline Social worker & 1 & 2 \\
\hline $\begin{array}{l}\text { Support for learning } \\
\text { staff }\end{array}$ & 11 & 24 \\
\hline Teacher & 39 & 50 \\
\hline $\begin{array}{l}\text { Third sector/ } \\
\text { voluntary sector } \\
\text { practitioner }\end{array}$ & 10 & 11 \\
\hline $\begin{array}{l}\text { Third sector/ } \\
\text { voluntary sector } \\
\text { volunteer }\end{array}$ & 2 & 9 \\
\hline $\begin{array}{l}\text { Prefer not to } \\
\text { answer }\end{array}$ & 2 & 2 \\
\hline Other & 11 & 21 \\
\hline
\end{tabular}

*When asked to select what was their profession, respondents were asked to select all that apply.

by the CYP are shown in figure 3 . Figure 4 shows the survey participants' postcodes matched with SIMD. A wide range of responses came from across the spectrum of the SIMD. The types and frequency counts of the learning difficulties categories are included in as online supplementary file 20 .

\section{Data processing and verifying uncertainties}

The 761 in-scope submissions were allocated into the nine themes. The first, second and last authors formulated 56 overarching preliminary indicative questions and 33 single questions out of the 761 original submissions. At the face-to-face meeting in December 2017, the steering group reviewed the 56 indicative and 33 single questions and considered whether the wording should be revised. The steering group agreed that some of the similar indicative questions could be further collapsed/merged together. The number of indicative questions were reduced from 56 to 37 . The steering group discussed and agreed that the majority of the single questions, except three questions, would be covered in the indicative questions. This created a total of 40 questions for prioritisation (also known as the long list). The steering group also agreed to classify four of the out-of-scope submissions as in-scope because they would be covered under the indicative questions. This reduced the number of out-of-scope submissions to 63 . All were confirmed as uncertainties as 

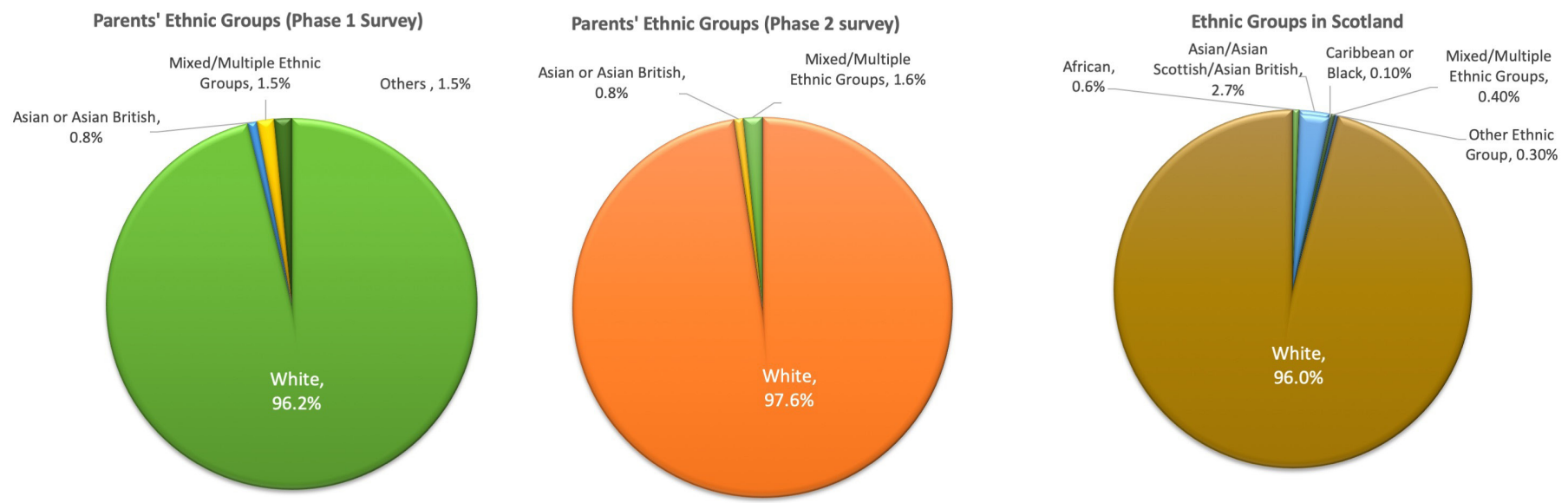

Figure 2 Parents' ethnic groups compared with ethnic groups in Scotland.

none of the existing research evidence could answer any of the 40 indicative questions.

\section{Interim priority setting (phase 2 survey)}

Reponses were received from 10 CYP with learning difficulties, 31 adults who experienced learning difficulties as a child, 125 parents/carers and 195 professionals (table 1). Scores were added across the family and professional groups resulting in a ranked list. The steering group considered the ratings and agreed to take Questions 1 to 24 and 26 to the final workshop. Question 25 'How can we make best use of resources to support children, young people and their families when a learning difficulty has been identified?' was not selected because it was ranked 30th and 20th positions by the family and professional groups, respectively. In comparison, Question 26 'Which strategies are effective in increasing the support available for CYP with learning difficulties, and their families/carers, in out-of-school activities?' was ranked 16th position by the family group. Members of the steering group who had conducted the interim priority setting survey in person with young people confirmed that this would ensure that issues that were important to them were included in the shortlist. Twenty-five questions were taken forward to the final prioritisation workshop.

\section{Final priority setting}

The 25 participants (4 males and 21 females; 2 Asian or British Asian and 23 White) included five young people, six parents, two speech and language therapists, one occupational therapist, one paediatrician, one consultant child and adolescent psychiatrist, two educational consultants, one additional support service leader, one pupil support assistant, one educational psychologist, one teacher, one additional support for learning teacher and two third sector professionals. Three of the young people were supported by their parent and another young person was supported by a pupil support assistant. The young people have their own clear ideas but needed help due to poor clarity of speech. The attendees were allocated to three pre-arranged discussion groups to ensure a balance of membership. The session started with a discussion of the pre-workshop ranking form before a formal attempt to create a ranking. The rankings from the first small groups were combined to create a shared ranking (table 2). Participants were then assigned to different groups to review and revise the shared ranked list. The results from the three groups were again combined, creating a new shared ranked list which was then discussed by the whole group in a plenary session. The participants
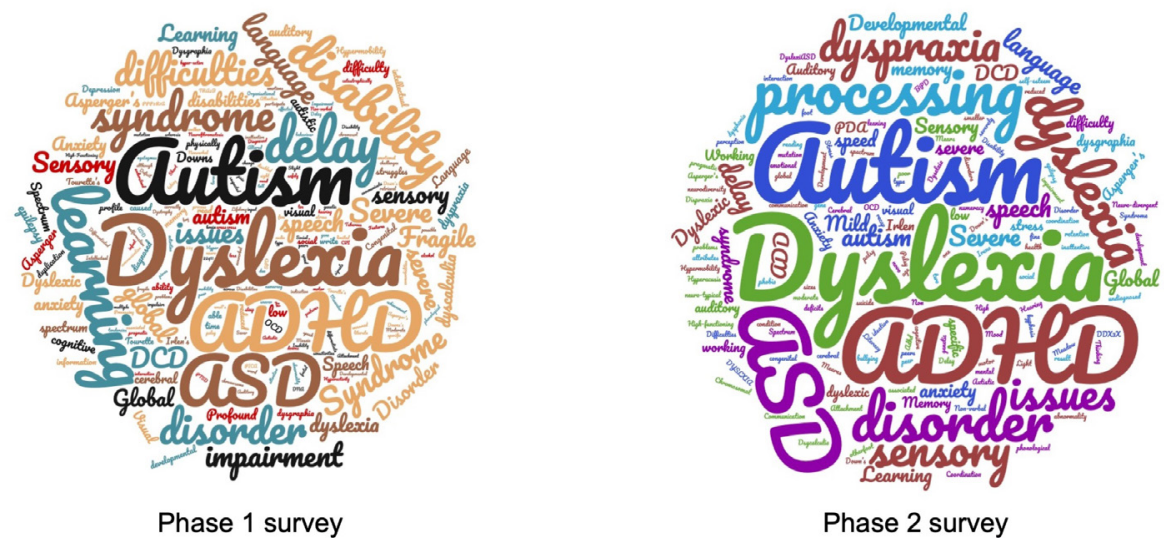

Figure 3 Types of learning difficulties experienced by children and young people. 

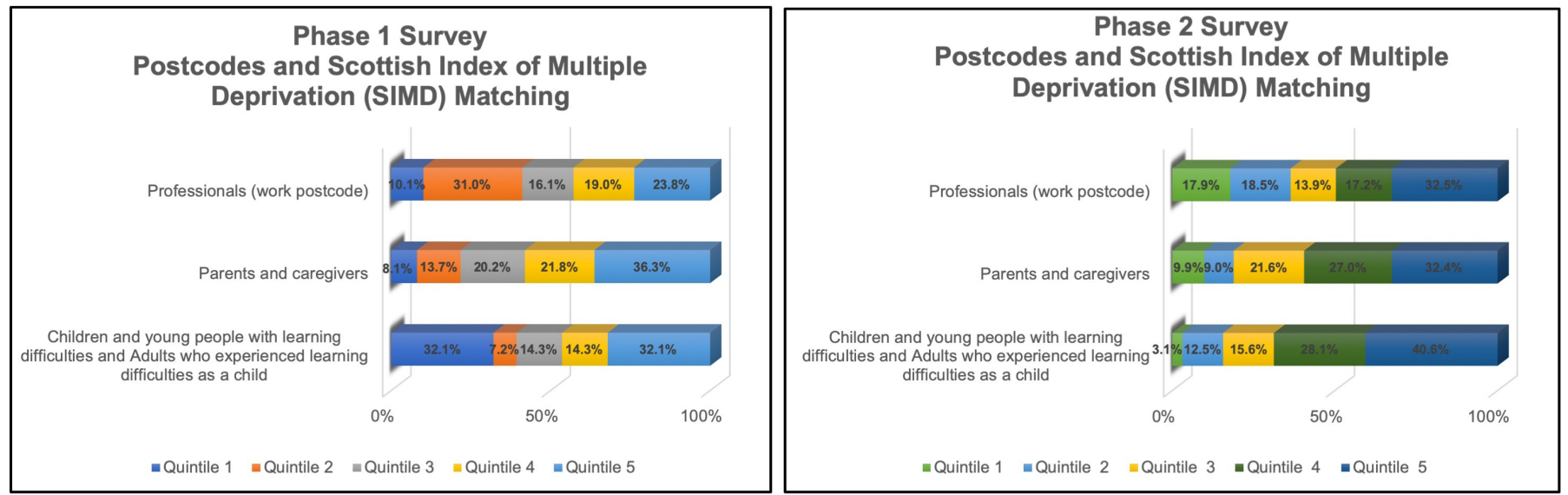

Figure 4 Postcodes and Scottish Index of Multiple Deprivation matching.

collectively agreed the final shortlist of top 10 research priorities (table 3). A modification was made to two of the questions. The group agreed to merge the question 'What are the best practices in planning for the future (ie, transition) for young people as they leave school in order to achieve the best possible employment prospects?' into the question 'Which strategies are effective in helping CYP with learning difficulties live independent lives?'. This reduced the shortlist to 24 questions that were prioritised from the workshop.

\section{DISCUSSION}

The JLA celebrated the completion of its 50th PSP in 2017. Many of these PSPs focus on heterogeneous, complex disorders and gather research questions ('uncertainties') that range beyond interventions (eg, autism, childhood disability and neurodevelopmental disorders PSPs). The learning difficulties PSP was unusual because it adopted a bespoke definition of 'learning difficulties' that was operationalised into categorical and non-categorical conditions to allow an evidence-based literature search, which is an essential component of the process. This was successful because the explanation of what we meant by learning difficulties for the purposes of the PSP resonated with those affected and brought together individuals affected by learning difficulties, their parents/carers and the professionals including those from education, who work alongside them to identify and rank questions they would like answered by research. Probably the nearest equivalent definition for 'learning difficulties' is the concept of Special Educational Needs, which in Scotland is enshrined in the devolved legislation as 'Additional Support for Learning' (Scotland) ${ }^{29}$ but as we had already demonstrated the variability with which this functional term was applied, this made it insufficient to capture the breadth of the childhood onset conditions that impair learning across all domains that we wanted to incorporate. ${ }^{30}$ The project succeeded in identifying the top 10 coproduced 'shared priorities' from a truly representative sample across geographical and socioeconomic sectors of the Scottish population and produced the short list of 24 questions to provide a platform for future research to focus on issues that matter most to CYP with learning difficulties, their parents/carers and the professionals who work alongside them. Although there were some concerns raised during the PSP with respect to the differences between learning difficulties and disabilities, and how those terms were being employed, ${ }^{24}$ this did not emerge as a prioritised question among the total 40 , although question ranked 15 did explore the impact of having a formal label or diagnosis.

We also demonstrated that the JLA process can accommodate a PSP that is not just examining a disease or infirmity but can approach health as 'a state of complete physical, mental and social well being, ${ }^{31}$ Public consultation in co-production of research priorities often results in questions around improving the lives of those affected, not just through the alleviation of symptoms signs and impairments but embracing the International Classification of Functioning, Disability and Health CYP concepts of involvement and participation. ${ }^{32}$ The top priority for the learning difficulties PSP is for research to find out 'what knowledge, skills and training do educational professionals need to identify the early signs of learning difficulties and provide optimal support for CYP affected to help them achieve the best possible outcomes'. We were successful in engaging education professionals across all categories from managers and education psychology to teachers and classroom assistants. However we do not consider that this resulted in the top question focusing on teachers skills, despite the results of a survey conducted by Scottish charity ENABLE which found that $98 \%$ of teachers said initial teacher training did not prepare them for teaching young people who have additional support for learning needs. ${ }^{13}$ This is because the JLA process is designed to balance contributions and prevent primacy of one particular group and the childhood disability PSP similarly had 'Which school characteristics (eg, policies, attitudes of the staff) are most effective to promote inclusion of CYP with neurodisability in education and after school clubs' despite only having two teachers among their contributing professionals. ${ }^{18}$ Rather we propose that 


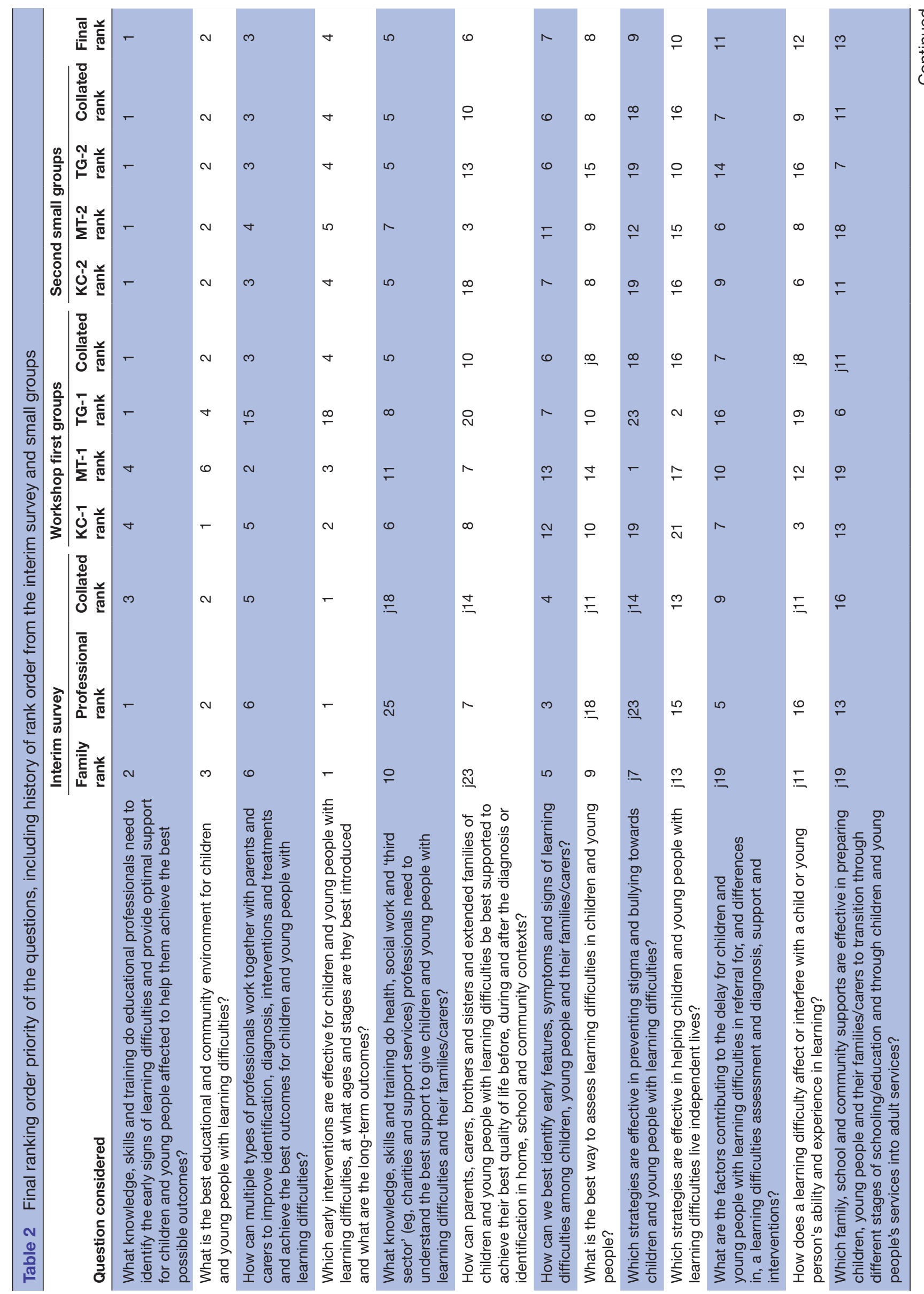

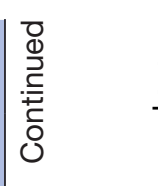




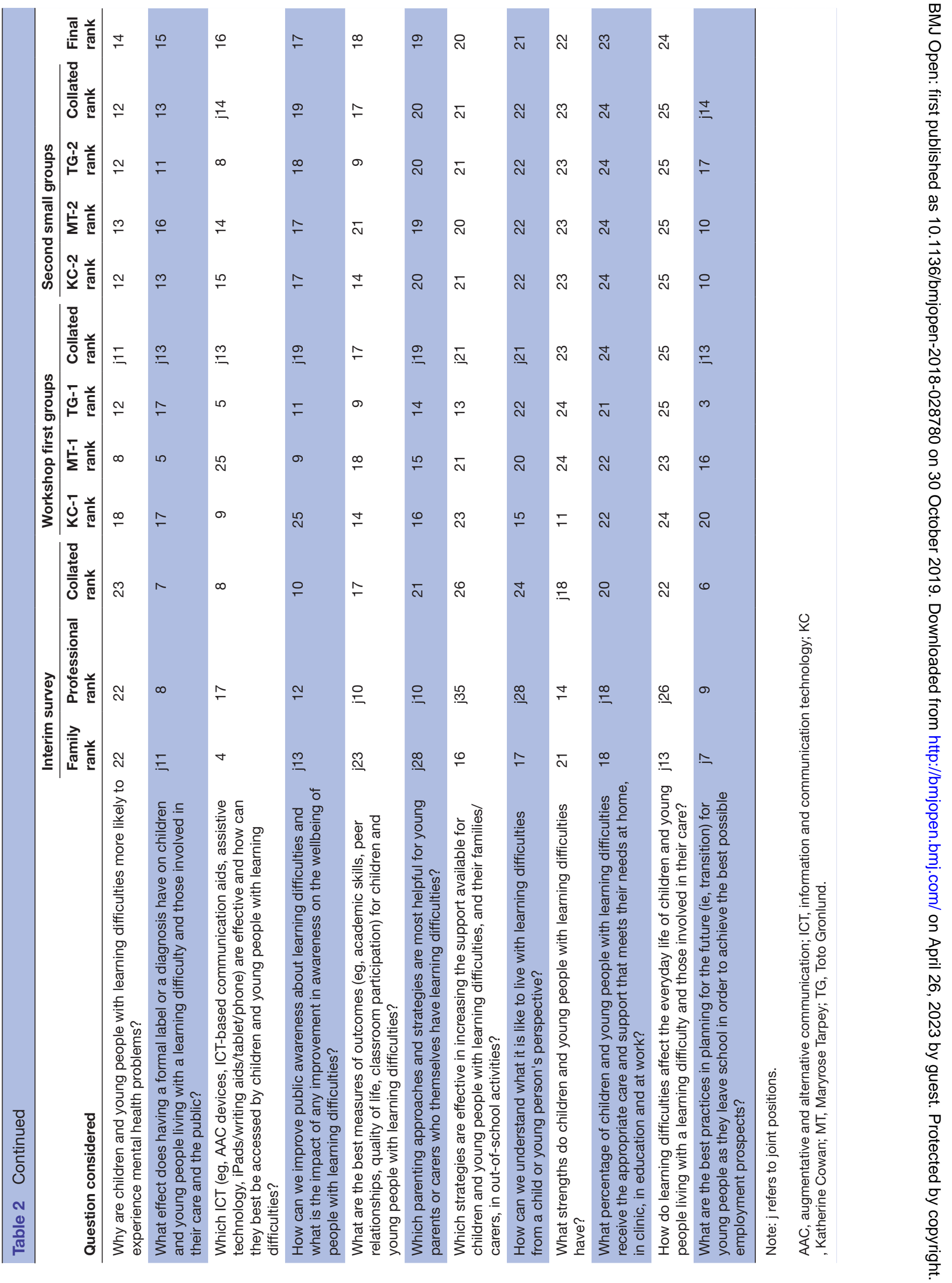


Table 3 Top 10 research questions agreed as shared priorities

(1) What knowledge, skills and training do educational professionals need to identify the early signs of learning difficulties and provide optimal support for children and young people affected to help them achieve the best possible outcomes?

(2) What is the best educational and community environment for children and young people with learning difficulties?

(3) How can multiple types of professionals work together with parents and carers to improve identification, diagnosis, interventions and treatments and achieve the best outcomes for children and young people with learning difficulties?

(4) Which early interventions are effective for children and young people with learning difficulties, at what ages and stages are they best introduced and what are the long-term outcomes?

(5) What knowledge, skills and training do health, social work and 'third sector' (eg, charities and support services) professionals need to understand the best support to give children and young people with learning difficulties and their families/carers?

(6) How can parents, carers, brothers and sisters and extended families of children and young people with learning difficulties, be best supported to achieve their best quality of life before, during and after the diagnosis or identification in home, school and community contexts?

(7) How can we best identify early features, symptoms and signs of learning difficulties among children, young people and their families/carers?

(8) What is the best way to assess learning difficulties in children and young people?

(9) Which strategies are effective in preventing stigma and bullying towards children and young people with learning difficulties?

(10) Which strategies are effective in helping children and young people with learning difficulties live independent lives, including during times of transition?

as CYP spend a large proportion of their lives at school and their experience there impacts on their health and well-being, this is an understandable priority for the learning difficulties PSP. ${ }^{33}$

The second priority also relates to finding the best educational and community environment for CYP with learning difficulties. A systematic review reported that community integration interventions were effective in enhancing the inclusion of children and adolescents with a neurodevelopmental intellectual disability. ${ }^{34}$ More research is needed to find out whether and which community participation interventions are most effective for CYP with other learning difficulties. The third priority underscores the importance of multi-professionals and multidisciplinary work. We will encourage researchers to find out how health, education and third sector professionals can continue to work together in improving the identification, diagnosis, interventions and treatments of CYP with learning difficulties. School is increasingly accepted as an important component of complex health interventions ${ }^{35}$ and particularly important for the maintenance of mental well-being. ${ }^{36}$ School-based information also has an important role in assessing outcomes ${ }^{37}$ and so it makes sense to understand how best to undertake and interpret this.

The learning difficulties PSP achieved more representation from CYP themselves than previous similar projects, and they comprised 1 in 5 of the final workshop participants. CYP have an increasing profile in public consultation in research ${ }^{38}$ but less so in setting the research agenda. ${ }^{39}$ We employed a range of techniques to secure their interest and engagement, but found that techniques such as focus groups were problematic for these young people who contended with oral and written language challenges. By ensuring the correct skill mix in the steering group we were able to exploit the skills of the OT and SLT and third sector representatives in particular to modify our materials, ${ }^{26}$ and to work individually with CYP with survey returns. Ranking the second survey was particularly challenging, but the project benefited directly from the expertise of the JLA team when it came to CYP contribution to the final rankings at the PSP workshop. We wanted to know that we had heard from CYP and the JLA facilitators' role was to bring those voices in and support people to contribute. We reflected on how this was going during the PSP workshop and also with the steering group after the workshop. We also took into account how the young people themselves defined the extent to which the experience was good or successful by asking for feedback from the young people through the JLA evaluation survey. The feedback was published on the JLA website.

The learning difficulties PSP received a lot of media coverage $^{40}$ and fed back directly to all those who participated and who expressed a desire to be kept informed. As the JLA focuses on giving individuals, carers and frontline professionals a say in setting the research agenda, ${ }^{21}$ researchers were less represented in the partnership. One of our dissemination plans is to communicate the results to interested researchers to help them focus their efforts on answering the highest priority questions. We will identify interested researchers through our networks and by searching the internet for research centres and university departments who may be interested in developing a proposal for one of the priority areas and submitting it to a funder. We encourage researchers and funders to share 
the learning difficulties PSP final report (online supplementary file 2) with others and to raise awareness of the need for more learning difficulties research in Scotland, the UK and internationally. Each overarching question comprises of many topics for research and the questions were written in plain language to make them lay-friendly. We will work with researchers to break down the broad overarching questions into smaller more manageable researchable questions. We expect funding agencies will be interested in the priority topics to influence directions for future research in this area. There were a number of highly ranked questions that addressed early identification and diagnosis, impact and assessment, prevention and understanding of high rates of co-existing mental health issues. There were questions that addressed epidemiology and aetiologies through understanding what constituted good outcomes to evaluate interventions and support, ranging from specific topics of communication technologies to transitions' support. These themes often overlap with those that have emerged in other PSPs in childhood disability $^{18}$ and autism in the $\mathrm{UK}^{19}$ and neurodevelopmental disorders ${ }^{41}$ and paediatric preventive care $^{42}$ in Canada. This adds weight to the research priorities that emerge in public consultation in childhood onset conditions that impair development or present challenges to learning and participation. While the answers are likely to involve researchers from multidisciplinary and multiagency backgrounds, mirroring what takes place clinically, they are health-related topics and already there is extensive involvement of health services in working with these populations. These frequently include lifelong conditions that impact beyond childhood, with research offering possibilities to improve the lives of individuals across the life span. ${ }^{43} 44$

A limitation of the study is the refined questions are broad and written in terms that a wide audience can understand, resulting mainly from the wide range of conditions covered by our definition of learning difficulties and the process of refining a large number of similar suggestions into a manageable shortlist of overarching questions. As a consequence, further work will be required to tease apart the overarching questions into topics (eg, conditions, causes, identification, diagnosis, effect on everyday life, what helps) that meet a research funders' requirements. Another limitation was that young people and adults with lived experience of learning difficulties were not represented in the steering group. The time taken to run a PSP typically take 12-18 months to complete. Given that members must have the time to commit to the work of the PSP both in the meetings and in between meetings, including publicising the initiative, overseeing the checking and collating of uncertainties and taking the final priorities to research funders, the steering group felt that it would be more meaningful to engage young people with learning difficulties and adults with lived experience of learning difficulties at different stages of the process, as discussed earlier.

\section{CONCLUSION}

This project used the JLA methodology to successfully produce a shortlist of prioritised topics in the area of learning difficulties among CYP. The involvement of individuals affected by learning difficulties not only has shaped how we conduct our research but also will influence practice and policy in this area. The next step is to encourage researchers and funding agencies to work together to address the prioritised topics as answering these questions would have profound effect on the lives of CYP with learning difficulties, their parents and carers and the professionals who work alongside them. We also encourage health and educational professionals to continue to work together and alongside researchers for the benefit of all people living with learning difficulties.

Assessing the long-term impact of the PSP is important. However, measuring and evaluating the value and impact of a PSP is challenging and can take a long time from taking the priorities to researcher funders, starting funded research to reporting the outcomes. ${ }^{26} \mathrm{JLA}$ will track which PSP-derived questions are addressed by NIHR programmes (both commissioned and researcher-led) but keeping track beyond that, from other funders and globally, is more difficult and will depend on whether the PSP core team has continued in any way. The Salvesen Mindroom Research Centre has mapped out similarities between the learning difficulties PSP and BACD childhood disability PSP and identified clear overlap within the top 10. This led to an initiation of a call for funding from early career BACD-Castang research fellows. The Salvesen Mindroom Research Centre also worked with BACD to develop research proposals that will address the fourth priority of the learning difficulties PSP and first priority of the childhood disability PSP. Several PSPs, including the childhood disability $\mathrm{PSP}^{45}$ and autism $\mathrm{PSP}^{46}$ have reported the impact of their work on the JLA website.

Acknowledgements We would like to thank The Salvesen Mindroom Centre for funding this project. We are grateful to all who contributed to the survey and prioritisation stages and participated in the final workshop. The authors would like to thank a large number of people who supported the project or helped with various tasks: the Learning Difficulties Priority Setting Partnership steering group members (Christine Carlin, Mandy Adamson, Sarah Clegg, Katherine Cowan, Gill Earl, Martin Gemmell, Gael Gordon, Leila Mackie, Margaret McPheely, Rosy Hume, Cathy Magee, Jay Shetty, Ereni Skouta, Justin Williams); Alison Irving, Engagement and Communications Officer, who helped with promotion and communication activities; and Toto Gronlund and Maryrose Tarpey, from James Lind Alliance, who facilitated groups at the final workshop.

Contributors All authors (AKL, SR, KC and $\mathrm{AO}$ 'H) made substantial contributions to the conduct of the Priority Setting Partnership, including promoting the survey and the acquisition, analysis and interpretation of data for the work. The steering group oversaw all aspects of the work. The project was managed by The Salvesen Mindroom Research Centre (AKL, SR and AO'H). AKL, SR and AO'H reviewed the research recommendations, coded the survey submissions and checked the uncertainties. All authors (AKL, SR, KC and $\mathrm{AO}$ ' $\mathrm{H}$ ) were involved in drafting and revising the papers, and approved the final version.

Funding This project was funded by The Salvesen Mindroom Centre.

Competing interests None declared.

Patient consent for publication Not required.

Provenance and peer review Not commissioned; externally peer reviewed. 
Data availability statement Further data regarding the source of the original submissions to the survey coded under each indicative question are available as online supplementary file 5 and in the learning difficulties (Scotland) page on the JLA website (http://www.jla.nihr.ac.uk/priority-setting-partnerships/learningdifficulties-scotland/downloads/Spreadsheet-Research-Priorities-for-LearningDifficulties-PSP.pdf).

Open access This is an open access article distributed in accordance with the Creative Commons Attribution Non Commercial (CC BY-NC 4.0) license, which permits others to distribute, remix, adapt, build upon this work non-commercially, and license their derivative works on different terms, provided the original work is properly cited, appropriate credit is given, any changes made indicated, and the use is non-commercial. See: http://creativecommons.org/licenses/by-nc/4.0/.

\section{ORCID iD}

Ai Keow Lim http://orcid.org/0000-0002-3189-0558

\section{REFERENCES}

1 Callander EJ. Pathways between health, education and income in adolescence and adulthood. Arch Dis Child 2016;101:825-31.

2 Valla L, Birkeland MS, Hofoss D, et al. Developmental pathways in infants from 4 to 24 months. Child Care Health Dev 2017;43:546-55.

3 Sonnander K. Early identification of children with developmental disabilities. Acta Paediatr 2000;89:17-23.

4 Guralnick MJ. Early intervention for children with intellectual disabilities: an update. J App/ Res Intellect Disabil 2017;30:211-29.

5 United Nations Children's Fund (UNICEF). Children with disabilities: The state of the world's children, 2013. Available: https://www.unicef org/sowc2013/files/SWCR2013_ENG_Lo_res_24_Apr_2013.pdf

6 European Agency for Special Needs and Inclusive Education. Dataset cross country report, 2014. Available: https://www.europeanagency.org/data/cross-country-report

7 Maulik PK, Mascarenhas MN, Mathers CD, et al. Prevalence of intellectual disability: a meta-analysis of population-based studies. Res Dev Disabil 2011;32:419-36.

8 Tweed EJ, Mackay DF, Nelson SM, et al. Five-minute Apgar score and educational outcomes: retrospective cohort study of 751369 children. Arch Dis Child Fetal Neonatal Ed 2016;101:F121-6.

9 Engle PL, Black MM. The effect of poverty on child development and educational outcomes. Ann N Y Acad Sci 2008;1136:243-56.

10 Shaw B, Bernardes E, Trethewey A, et al. Special educational needs and their links to poverty. Joseph Rowantree Foundation Inspiring social change, 2016. Available: https://www.jrf.org.uk/report/specialeducational-needs-and-their-links-poverty [Accessed 30 Oct 2018].

11 White J. Children's social circumstances and educational outcomes - Evidence summary, 2018. Available: http://www.healthscotland. scot/media/2049/childrens-social-circumstances-and-educationaloutcomes-briefing-paper.pdf

12 Emerson E, Hatton C, Baines S, et al. The physical health of British adults with intellectual disability: cross sectional study. Int J Equity Health 2016;15:11 https://dx.doi.org/10.1186\%2Fs12939-016-0296-

13 Enable Scotland. \#IncludED in the Main?! 22 steps on the journey to inclusion for every pupil who has a learning disability, 2016. Available: https://www.enable.org.uk/wp-content/uploads/2017/08/ IncludED-in-the-Main-22-Steps-on-the-Journey-to-Inclusion.pdf [Accessed 30th July 2018].

14 Shiels N, King M, Corbett M, et al. Is participation among children with intellectual disabilities in outside school activities similar to their typically developing Peers? A systematic review. Dev Neuro rehabil 2014;17:64-71.

15 The Salvesen Mindroom Centre. n.s. learning difficulty or learning disability. Available: http://www.mindroom.org/index.php/learning difficulties/what_are_learning_difficulties/learning_difficulty_or_ learning_disability [Accessed 26th July 2018].

16 Kovachy VN, Adams JN, Tamaresis JS, et al. Reading abilities in school-aged preterm children: a review and meta-analysis. Dev Med Child Neurol 2015;57:410-9.

17 Thompson L, Kemp J, Wilson P, et al. What have birth cohort studies asked about genetic, pre- and perinatal exposures and child and adolescent onset mental health outcomes? A systematic review. Eur Child Adolesc Psychiatry 2010;19:1-15.

18 Morris C, Simkiss D, Busk M, et al. Setting research priorities to improve the health of children and young people with neurodisability: a British Academy of Childhood Disability-James Lind Alliance research priority setting partnership. BMJ Open 2015;5:e006233.

19 Autistica. Your questions: shaping future autism research. Available: https://www.autistica.org.uk/downloads/files/Autism-Top-10-YourPriorities-for-Autism-Research.pdf
20 JLA. The James Lind alliance. Available: http://www.jla.nihr.ac.uk [Accessed 26th July 2018].

21 Barnieh L, Jun M, Laupacis A, et al. Determining research priorities through partnership with patients: an overview. Semin Dial 2015;28:141-6.

22 British Institute of Learning Disabilities. Factsheet: learning disability. Available: https://www.google.com/url?sa=t\&rct=j\&q=\&esrc=s\& source $=$ web\&cd $=10 \&$ cad $=$ rja\&uact $=8 \&$ ved $=2$ ahUKEwjVgaHHq7 cAhVBCMAKHWr4BoEQFjAJegQIABAC\&url=http\%3A\%2F\%2Fwww. csp.org.uk\%2Fsites\%2Ffiles\%2Fcsp\%2Fsecure\%2Flearning disabilities_bild.pdf\&usg=AOvVaw2492Ozqfq_cUeyy4Rz4q1E [Accessed 26th July 2018].

23 British Institute of Learning Disabilities. Definitions of learning disability and learning difficulties. Available: https://www.google. com/url?sa $=$ t\&rct $=j \& q=\& e s r c=s \&$ source $=$ web\&cd $=9 \&$ ved $=$ 2ahUKEwjVgaHHq7_cAhVBCMAKHWr4BoEQFjAlegQIARAC\& url=http $\% 3 A \% 2 F \% 2 F w w w . b i l d . o r g . u k \% 2 F E a s y S i t e W e b \%$ 2FGatewayLink.aspx\%3Falld\%3D3961\&usg=AOvVaw2E6P18ug6hHCosnBt2PGy [Accessed 26th July 2018].

24 Tuck J. Developmental disabilities: labelling and definitions. classifications, conceptualisations, confusion - and clarity? the bridge, issue 1. The Association for Child and Adolescent Mental Health 2014.

25 Lindsay G. Inclusive education theory and practice: what does this mean for paediatricians? Paediatr Child Health 2018;28:368-73.

26 James Lind Alliance. The James Lind alliance Guidebook, 2018. Available: http://www.jla.nihr.ac.uk/jla-guidebook/downloads/ Version-8-JLA-Guidebook-for-download-from-website.pdf [Accessed 31st July 2019].

27 American Psychiatric Association. Diagnostic and statistical manual of mental disorders. 5th Ed. Washington, DC: American Psychiatric Association, 2013.

28 World Health Organisation. International Classification of Diseases, 11th Revision (ICD-11). Available: https://icd.who.int/browse11/l-m/ en

29 Education. (additional support for learning) (Scotland) act, 2009. Available: http://www.legislation.gov.uk/asp/2009/7/pdfs/asp_ 20090007_en.pdf

30 Lebeer J, Birta-Székely N, Demeter K, et al. Re-Assessing the current assessment practice of children with special education needs in Europe. Sch Psychol Int 2012:33:69-92.

31. World Health Organisation. Constitution of the World Health Organisation - principles. Available: http://apps.who.int/gb/bd/PDF/ bd47/EN/constitution-en.pdf?ua=1

32 Imms C, Adair B, Keen D, et al. 'Participation': a systematic review of language, definitions, and constructs used in intervention research with children with disabilities. Dev Med Child Neurol 2016;58:29-38

33 Marryat L, Thompson L, Minnis $\mathrm{H}$, et al. Primary schools and the amplification of social differences in child mental health: a population-based cohort study. J Epidemiol Community Health 2018;72:27-33.

34 Andrews J, Falkmer M, Girdler S. Community participation interventions for children and adolescents with a neurodevelopmental intellectual disability: a systematic review. Disabil Rehabil 2015;37:825-33.

35 Green J, Aldred C, Charman T, et al. Paediatric Autism Communication Therapy-Generalised (PACT-G) against treatment as usual for reducing symptom severity in young children with autism spectrum disorder: study protocol for a randomised controlled trial. Trials 2018;19:514.

36 Paulus FW, Ohmann S, Popow C. Practitioner review: school-based interventions in child mental health. Journal of Child Psychology and Psychiatry 2016;57:1337-59.

37 Martel MM, Markon K, Smith GT. Research review: Multi-informant integration in child and adolescent psychopathology diagnosis. $J$ Child Psychol Psychiatr 2017;58:116-28.

38 Royal College of Paediatrics and Child Health (RCPCH). Involving children and young people in health services, 2012. Available: https://www.rcpch.ac.uk/sites/default/files/RCPCH-involving-cyp-inhealth-services-2012.pdf

39 Odgers HL, Tong A, Lopez-Vargas P, et al. Research priority setting in childhood chronic disease: a systematic review. Arch Dis Child 2018;103:942-51.

40 James Lind Alliance (JLA). PSP articles and publications: learning difficulties (Scotland). Available: http://www.jla.nihr.ac.uk/news-andpublications/psp-articles-and-publications.htm\#LD

41 Ontario Brain Institute. Top 10 research priorities for neurodevelopmental disorder, 2017. Available: http://www. braininstitute.ca/programs-opportunities/setting-research-priorities/ neurodevelopmental-disorders-psp 
42 Lavigne M, Birken CS, Maguire JL, et al. Priority setting in paediatric preventive care research. Arch Dis Child 2017;102:748-53.

43 Sourander A, Jensen P, Ronning JA, et al. What Is the Early Adulthood Outcome of Boys Who Bully or Are Bullied in Childhood? The Finnish "From a Boy to a Man" Study. Pediatrics 2007;120:397-404.

44 Copeland WE, Wolke D, Angold A, et al. Adult psychiatric outcomes of bullying and being bullied by peers in childhood and adolescence. JAMA Psychiatry 2013;70:419-26.
45 British Academy of Childhood Disability. Childhood disability PSP: what happens after a PSP has identified its priorities? 2015 Available: http://www.jla.nihr.ac.uk/news/what-happens-after-a-psphas-identified-its-priorities/3485

46 Autistica. Autism PSP update from Autistica at the end of 2016: the progress made so far on each of the top 10 questions, 2017. Available: https://us10.campaign-archive.com/?u=2e994d37c540 c508748a37a76\&id $=405 f 2384$ e6\&e $=0208 \mathrm{e} 6 \mathrm{c} 888$ 